\title{
Bioethical Challenges at the Beginning of 21st Century in Education of Healthcare Professionals
}

\author{
M. Mojzesova (Maria Mojzesova)1,2, 5. Capikova (Silvia Capikova)2, J. Trizuljakova \\ (Jana Trizuljakova)
}

${ }^{1}$ St. Elizabeth University of Health and Social Work in Bratislava, SK

Original Article

${ }^{2}$ Institute of Social Medicine and Medical Ethics, Comenius University in Bratislava, Faculty of Medicine, SK

\section{E-mail address:}

maria.mojzesova@fmed.uniba.sk

\section{Reprint address:}

Maria Mojzesova

St. Elizabeth University of Health and Social Work in Bratislava

Nam. 1. Maja 1

80010 Bratislava

SK

Source: Clinical Social Work and Health Intervention

Pages: $67-70$
Volume: 9

Issue: 1

\section{Reviewers:}

Maria Zamboriova

Faculty of Medicine, Department of Nursing Care, P. J. Safarik University in Kosice, SK

Andrea Pokorna

Masaryk University, Brno, CZ

\section{Key words:}

Bioethics. Humanization of Medicine. Education of Healthcare Professionals. Intersectional concept of education.

\section{Publisher:}

International Society of Applied Preventive Medicine i-gap

CSWHI 2018; 9(1): 67 - 70; DOI 10.22359/cswhi_9_1_10 @ 2018 Clinical Social Work and Health Intervention

\section{Abstract:}

This paper is analyzing selected contemporary bioethical challenges within healthcare delivery. The main challenge for contemporary Health Professionals is to develop critical thinking and apply a holistic 
approach for persons in various phases of their daily professional performance. The authors introduce the interdisciplinary concept of education in bioethical problems at FM CU in Bratislava. Intersectional education in the humanities in undergraduate training for Healthcare Professionals allows optimization of professional skills for the graduates, following the "Humanization of Medicine" as a longitudinal trend.

\section{Introduction}

The main challenge for contemporary Physicians, Nurses and other Healthcare Professionals is to apply a holistic approach to persons in any phases of their daily professional performance. Fast technological development opens the doors to depersonalization or dehumanization of Medical or Nursing Care especially for those who are most vulnerable. There are patients who are near the end of life; terminally ill with oncologic, neurodegenerative or other life-limiting diseases; but also chronically ill or handicapped individuals, pregnant women, prenatal and postnatal children, people of older age, etc. (Kosticova, 2015).

Rapid developments in the Medical field in the last century have revolutionized Medical and Nursing Practice. Life expectancy has been prolonged; many infectious diseases have been eliminated; genetic defects can be detected in utero or in vitro; organs and cells can be transplanted; human reproduction can be controlled; pain can be relieved. Besides all these developments, Physicians and Nurses in many developed countries are facing many challenges in the practice of their professions.

An ethical decision is not just about providing the best clinical outcome for the patient but involves a search for coherent solutions in situations where different people's interests or priorities conflict. It is often as concerned with the process through which a decision is reached as with the decision itself taking into account ethical standards, law and quasi law (Sommerville, 2016).

\section{Medicine Together with Nursing and an Holistic Approach to the Sick}

The anatomy of the "old" Medicine and Healthcare was within the autonomy of healing. In the tradition of Hippocrates and Judeo-Christian values of European Healthcare and Medicine, the Doctor (Physician) was a Healer, nothing more but nothing less. The ethical imperative for them pledged to do no harm to their patients as they sought to do only good. With the eclipsing of paternalism by autonomy of a patient, the authority and ethical responsibility of the Physician or Nurse has changed and the duties of beneficence have become more apparent and necessary (Mojzesova et al., 2015).

The "new Medicine": a "winning Medicine" concentrates on cellular and subcellular level of human body. It uses biotechnologies for the improvement of human health, but also omits holistic approaches to the incurable human; to the terminally ill; to the unborn; to all who need help, protection, support or rescue. Medicine and Healthcare was transformed from individual art to institutionalized application of specialized technology.

However, disease is an attack on the whole person. Unfortunately, depersonalization and subsequently dehumanization are constant "treatment" in contemporary technologically oriented Healthcare (Pellegrino, 1980). The holistic approach requires to respect a human person in four dimensions (levels) of her/him: 1) somatic (bodily), 2) 
psychic, 3) spiritual and 4) social. (Trizuljakova, 2016, Kosticova, 2015). Holistic Medicine Practitioners are sure that the whole person is made up of interdependent parts and if one part is not working properly, all the other parts will be affected. In this way, if people have imbalances (physical, emotional, or spiritual) in their lives, these can negatively affect their overall health.

\section{The Bioethical Challenges for Education of Healthcare Professionals}

One also can see the relativization and weakening of traditional moral values in contemporary Healthcare. It is important to consider new biomedical technologies with concern for many ethical dilemmas in medically assisted human reproduction; human fertility regulation; regenerative Medicine; creation of hybrids or chimeras; contemporary science and high technologies. Medicine without tight connection with ethics is comparable with plant without water. Undergraduate students should be educated with attention on humanitarian subjects, not only on preclinical or clinical ones.

The moral integrity of Healthcare Professionals should be strengthened by permanent ethical and bioethical education and training. The basic questions in the teaching process in general are: Why? What? How? The basic premise is that the learning or teaching process must be selective and integrative. The challenge is to provide sound education in the art of Medicine; in the art of healing; in an art of treatment; in the art of listening to the sick; in the art of communication with patients, their relatives, and with colleagues.

Education in human values and ethics seems as a guarantee for entering into the 21 st century, as new and new moral dilemmas are still emerging and "ready-to-use answers" are not available. It is optimal when undergraduate education of future Health Professionals has an intersectional character.

\section{The Example of Intersectional Education at Fm Cu in Bratislava}

Teaching of an obligatory subject Medical Ethics at the Faculty of Medicine within Comenius University in Bratislava, capital of Slovakia, is part of intersectional concept of undergraduate education of future Medical Doctors. Semi-compulsory subjects like "Introduction to Medical Law" and "Communication Skills" need to be included in this concept, too. In these subjects Teachers concentrate on holistic approaches to human beings in health and disease. The content of topics is oriented on subjects of Healthcare interests - on the human individual; on the dignity of human person from ethical point of view; on the necessity of respecting human dignity according to selected international or national legislation; the doctrine of informed consent etc..

Human dignity is considered guaranteed and a starting point for all human rights. A correct understanding and respect for human dignity becomes a protection for human life during its ontogenesis from fertilization to the natural death. Medical students as future Health Professionals are led to critical thinking, so they participate on open discussions, debates and polemics about selected bioethical topics; about ethical dilemmas in connection with the beginnings of human life (prenatal diagnostics, preimplantation genetic diagnostics, new technological possibilities within in vitro fertilization laboratory methods, research with participation of early human embryos); or with end of human life issues (about palliative care vs. euthanasia). Topics include rights of patients; truth telling and hope for those who suffer; belong to limitations both of a patient and of professional autonomy of Healthcare Professionals are explained to students not only from an 
ethical point of view, but from legal, too. Communication skills are considered as one of the instruments of a Health Professional.

\section{Conclusion}

The optimal relationships between Healthcare Professionals and their patients are based on excellence in actual scientific knowledge and erudition, practical skills and optimal ethical attitudes. Modern society often ignores or refuses basic human values. The bioethical challenges for contemporary education of Healthcare Professionals are based on respect for all human beings during their ontogenesis from the beginning to the end of their lives becomes an aim of the Profession. Clinical reasoning is a complex matter, thus, education of Health Professionals should be designed as intersectional among subjects within the curricula.

\section{References}

1. KOSTICOVA M (Ed.) (2015) Social Medicine. Comenius University in Bratislava:
Bratislava, 184 p. ISBN $978-80-223-$ 3935 - 3.

2. MOJZESOVS M (Ed.) (2015) Public Health Ethics - Selected Issues. Comenius University in Bratislava: Bratislava, ISBN $978-80-223-3937-7$.

3. OLAH M (Ed.) (2016) Alternative child custody ,Cochem's model“. Nadlac. Editura Ivan Krasko, 1. ed. 2016. pp. 221. ISBN 9789731071060.

4. PELlEGRINO E D (1981) A Concept of Professional Ethics in Medical Education (p. 172-181). In: Medical Ethics and Medical Education. Proceedings of the XIVth Round Table Conference, Mexico City, Mexico, 1-3 Dec.1980. (Eds. Bankowski, Z. and Bernadelli, J. C.), 281 p. ISBN 978-929036-006-3.

5. SOMMERVILLE A (2013) Everyday Medical Ethics and Law.1st ed. Wiley-Blackwell, 297 p. ISBN 978-1-118-38489-3.

6. TRIZULJAKOVA J et al (2017) Medical ethics - selected chapters. part 1. 1. ed. Bratislava: University of Comenius. 232 p. ISBN 978-80-223-4093-9. 